\title{
Hubungan Perubahan Fisik Ruang dengan Kondisi Sosial Ekonomi Masyarakat di Kawasan Koridor Aglomerasi Mertoyudan, Kabupaten Magelang
}

\author{
Nursanti Anggraeni ${ }^{\mathbf{1}}$ \\ PT. Trikarsa Buwana Persada Gemilang \\ Ungaran, Kabupaten Semarang, Indonesia

\section{Broto Sunaryo} \\ Jurusan Perencanaan Wilayah dan Kota \\ Fakultas Teknik, Universitas Diponegoro, Semarang, Indonesia
}

Artikel Masuk : 28 Mei 2015

Artikel Diterima : 3 Juli 2015

Tersedia Online : 31 Agustus 2015

\begin{abstract}
Abstrak: Aglomerasi perkotaan merupakan salah satu faktor yang mempengaruhi perkembangan kawasan koridor Mertoyudan. Penelitian ini bertujuan untuk mengkaji hubungan perubahan fisik ruang dengan kondisi sosial ekonomi masyarakat di kawasan koridor Mertoyudan sebagai implikasi aglomerasi perkotaan. Teknik analisis deskriptif kuantitatif dilakukan melalui analisis tabulasi silang. Hasil penelitian menunjukkan bahwa pengaruh aglomerasi terhadap perkembangan fisik kawasan terlihat dari tingginya konsentrasi lahan terbangun di sepanjang koridor Mertoyudan. Di samping itu, perubahan mata pencaharian dari sektor agraris ke nonagraris penduduk juga meningkat dan meningkatkan tingkat pendapatan penduduk di kawasan koridor Mertoyudan. Namun demikian, aglomerasi perkotaan kurang berimplikasi pada frekuensi mobilitas penduduk dan tidak berdampak pada frekuensi interaksi sosial karena aglomerasi perkotaan di kawasan koridor Mertoyudan masih dalam fase awal. Untuk itu, penelitian ini menyimpulkan bahwa ada hubungan antara aspek fisik dengan beberapa aspek sosial ekonomi masyarakat akibat aglomerasi perkotaan.
\end{abstract}

Kata Kunci: aglomerasi perkotaan, koridor Mertoyudan, perubahan fisik ruang, sosial-ekonomi

\begin{abstract}
Urban agglomeration is one of the factors that influence the development of Mertoyudan corridor. The research investigates the correlation of the physical change to socio-economic conditions of inhabitants in Mertoyudan corridor as the implications of urban agglomeration. A quantitative descriptive analysis applied by using crosstab analysis. The results show that the impact of agglomeration on the physical development is demonstrated by the high concentration of built-up area along Mertoyudan corridor. In addition, the change of livelihood from the agricultural sector to nonagricultural sector also increase and raising the income level of Mertoyudan corridor inhabitants. However, the urban agglomeration has the less impact to the mobility frequency and has no implication to the social interaction frequency because the urban agglomeration is still in initial phase. Therefore, this research
\end{abstract}

\footnotetext{
${ }^{1}$ Korespondensi Penulis: PT. Trikarsa Buwana Persada Gemilang, Ungaran, Kab. Semarang, Indonesia Email: anggraeni.nursanti27@gmail.com
} 
Hubungan Perubahan Fisik Ruang dengan Kondisi Sosial Ekonomi Masyarakat...

suggests that there is a relationship between the physical aspect with some of the socioeconomic variables, i.e. the land use change, livelihood change, and income level due to the urban agglomeration.

Keywords: urban agglomeration, Mertoyudan corridor, change of physical space, socioeconomic

\section{Pendahuluan}

Ketersediaan ruang bagi suatu wilayah merupakan modal pengembangan karena setiap wilayah membutuhkan ruang untuk mewadahi segala aktivitas di dalamnya. Semakin pesatnya perkembangan suatu wilayah, maka permasalahan keterbatasan ruang bukan terbangun seringkali menjadi kendala perkembangan seiring dengan bertambahnya jumlah penduduk yang harus dilayani, mulai dari penyediaan ruang bermukim hingga ruang aktivitas sosial dan ekonomi. Kondisi demikian salah satunya terjadi di Kota Magelang. Dengan luas wilayah yang relatif kecil, ditambah perkembangan Kota Magelang tumbuh dengan pesat, terjadi keterbatasan ruang di Kota Magelang yang menyebabkan perkembangan kota bergerak ke arah selatan, yakni ke wilayah Kabupaten Magelang. Dari pergeseran perkembangan Kota Magelang tersebut, terjadi aglomerasi di koridor Mertoyudan, Kabupaten Magelang.

Menurut Montgomery (dalam Kuncoro, 2002), aglomerasi adalah konsentrasi spasial dari aktivitas ekonomi di kawasan perkotaan karena penghematan akibat lokasi yang berdekatan yang diasosiasikan dengan klaster spasial dari perusahaan, para pekerja, dan konsumen. Kuncoro juga menyatakan bahwa industri cenderung beraglomerasi di daerahdaerah dimana potensi dan kemampuan daerah tersebut memenuhi kebutuhan mereka, dan mereka mendapat manfaat akibat lokasi perusahaan yang saling berdekatan. Dengan aglomerasi, para pelaku industri dapat melakukan penghematan ekonomi (agglomeration economies) seperti yang dikonsepkan oleh Marshall (dalam McDonald, 1997). Serupa dengan Weifeng, Chuanglin, dan Jitao (2008) bahwa aglomerasi perkotaan adalah derajat konsentrasi spasial, dimana konsentrasi ini dibentuk karena ada kesamaan ekonomi dan teknologi dalam proses pembentukan dan pengembangan aglomerasi perkotaan. Lebih lanjut Weifeng, Chuanglin, dan Jitao (2008) menjelaskan bahwa aglomerasi perkotaan dapat diibaratkan seperti kota kompak yang memanfaatkan sumber daya secara lebih intensif dan efisien. Perkembangan spasial dalam aglomerasi perkotaan terjadi karena ada kota-kota dengan ukuran berbeda sehingga perlu ada pengklusteran kota (Gan, Ping-yu, \& Bin, 2006). Dalam aglomerasi perkotaan industri ditunjukkan bahwa ada konsentrasi atau pengklusteran industri dengan jenis industri, teknologi, dan aktivitas ekonomi yang saling terkait. Dengan demikian, aglomerasi perkotaan merupakan konsentrasi spasial dari aktivitas ekonomi pada suatu kawasan yang mengelompok sehingga pelaku usaha dapat memanfaatkan resource yang sama.

Pada kondisi eksisting saat ini, koridor Mertoyudan didominasi oleh aktivitas perdagangan dan jasa. Pesatnya perkembangan aktivitas perdagangan dan jasa di koridor Mertoyudan merupakan akibat adanya dorongan dari Kota Magelang dengan dukungan infrastruktur wilayah berupa jalur nasional sebagai akses utama yang menghubungkan wilayah Jawa Tengah dengan Provinsi DIY. Bertumpu pada definisi aglomerasi, jalan arteri nasional koridor Mertoyudan tersebut merupakan salah satu resource yang digunakan bersama dalam menunjang aktivitas ekonomi yang terkonsentrasi di koridor perkotaan tersebut. Jaringan transportasi berperan penting dalam pembentukan kluster perkotaan. Jaringan transportasi mampu meningkatkan pertumbuhan ekonomi perkotaan terkait dengan pasar dan politik (Gan, Ping-yu, \& Bin, 2006; Chuanglin, Jitao, \& Dunjiang, 2007). 
Selain memanfaatkan aksesibilitas jalan arteri nasional sebagai resource bersama, aglomerasi perkotaan di koridor Mertoyudan juga memanfaatkan banyak tenaga kerja lokal, yaitu masyarakat lokal yang bertempat tinggal di kawasan koridor Mertoyudan. Hal tersebut tampak dimana aglomerasi yang terjadi di koridor Mertoyudan memberikan implikasi terhadap perubahan fisik ruang serta sosial ekonomi masyarakat secara signifikan. Dari sisi perubahan fisik ruang, sebagaimana telah disinggung bahwa aglomerasi perkotaan di koridor Mertoyudan telah menyebabkan tingginya aktivitas ekonomi yang berarti bahwa terjadi perubahan intensitas lahan terbangun di koridor Mertoyudan. Akibatnya, perubahan fisik ruang juga mengarah pada perubahan fungsi lahan yang semula nonkomersial menjadi fungsi komersial. Sedangkan dari aspek sosial ekonomi masyarakat, aglomerasi di koridor Mertoyudan menyebabkan perubahan mata pencaharian masyarakat dari sektor pertanian ke sektor nonpertanian yang didominasi oleh sektor perdagangan dan jasa. Selain itu, aglomerasi di koridor Mertoyudan juga berpengaruh pada frekuensi mobilitas masyarakat dan interaksi sosial antar masyarakat. Tingginya aktivitas ekonomi di Koridor Mertoyudan telah membuka peluang kerja yang tinggi bagi masyarakat lokal sehingga terjadi pula peruabahan jarak lokasi aktivitas mayarakat. Frekuensi mobilitas masyarakat juga cenderung meningkat semakin sering seiring dengan semakin pesatnya aktivitas di koridor Mertoyudan. Dari sisi ekonomi, aglomerasi di koridor Mertoyudan menyebabkan bergesernya struktur ekonomi kawasan yang dapat dilihat dari sektor-sektor perekonomian. Selain itu, aglomerasi di koridor Mertoyudan juga mendongkrak meningkatnya pendapatan di sektor nonpertanian. Sebagai dampaknya adalah peningkatan pendapatan masyarakat di wilayah sekitar yang beraktivitas di koridor Mertoyudan.

Belum banyak penelitian mengenai aglomerasi perkotaan yang memiliki fokus pada aspek keruangan atau fisik, seperti Weifeng, Chuanglin, dan Jitao (2008) yang membahas mengenai perlunya kompaksitas dalam aglomerasi perkotaan; Rongchao, Changhong, Xuexin, dan Deguang (2007) yang menenkankan pada perlunya penerapan struktur ruang eco-spasial pada aglomerasi perkotaan untuk menjamin keberlanjutan; dan Gan, Ping-yu, dan Bin (2006) yang menganalisis kronologi dan dinamika aglomerasi perkotaan di China menggunakan indikator kondisi geografi, ekonomi, latar belakang kebijakan, dan kondisi lalu lintas yang mengindikasikan bahwa kondisi geografis berperan penting dalam menentukan perkembangan ekonomi dan infrastruktur. Untuk itu, belum ada penelitian yang secara spesifik mengkaitkan dampak perubahan fisik ruang dengan kondisi sosial ekonomi masyarakat pada wilayah terdampak aglomerasi perkotaan. Dari keterbatasan penelitian yang ada, maka penelitian bertujuan untuk mengkaji hubungan perubahan fisik ruang dengan kondisi sosial ekonomi masyarakat di kawasan koridor Mertoyudan sebagai implikasi aglomerasi perkotaan. Penelitian ini dibatasi pada hubungan perubahan fisik ruang yang diidentifikasi melalui penggunaan dan fungsi lahan terhadap variabel sosial ekonomi meliputi mata pencaharian, tingkat penghasilan, frekuensi mobilitas, dan frekuensi interaksi. Dengan dilakukannya penelitian yang disajikan secara kuantitatif melalui analisis tabulasi silang ini, diharapkan dapat diperoleh informasi mengenai seberapa besar fenomena aglomerasi di koridor Mertoyudan menyebabkan perubahan fisik ruang dan perubahan sosial ekonomi masyarakat, serta model hubungan antar variabel-variabel penelitian yang akan dikaji.

\section{Metode Penelitian}

Penelitian dilakukan dengan menggunakan pendekatan positivistik, dimana teori digunakan sebagai landasan pelaksanaan penelitian yang kemudian diujikan dengan kondisi empiris yang ada di wilayah penelitian, yaitu koridor Mertoyudan. Metode penelitian yang digunakan adalah kuantitatif untuk mengkaji sampel dengan menggunakan instrumen, teknik pengumpulan data, dan teknik analisis yang bersifat kuantitatif atau 
statistik. Pengumpulan data dilakukan secara primer (kuesioner, wawancara, dan observasi lapangan) dan secara sekunder (telaah dokumen instansi). Teknik sampling yang digunakan adalah proporsionated area purposive sampling, dimana sampel yang diambil adalah masyarakat lokal yang terdampak aglomerasi perkotaan di Koridor Mertoyudan. Kuesioner digunakan untuk menggali informasi mengenai pendapatan, kondisi pergerakan, dan interaksi sosial dengan masyarakat sekitar. Wawancara dilakukan kepada beberapa instansi seperti Bappeda Kota Magelang untuk menggali informasi tentang langkah yang dilakukan untuk mengantisipasi fenomena aglomerasi yang terjadi. Observasi lapangan dilakukan untuk melihat kondisi fisik, penggunaan lahan, dan jenis aktivitas perekonomian yang berkembang di Koridor Mertoyudan. Data yang diperoleh dari sampel dianalisis dengan menggunakan teknik analisis deskriptif kuantitatif dan analisis statistik dengan metode tabulasi silang (crosstab) untuk mengkaitkan hubungan serta mengetahui pola hubungan antara perubahan fisik ruang dengan sosial ekonomi masyarakat sebagai implikasi aglomerasi perkotaan di Koridor Mertoyudan.

\section{Gambaran Umum}

\section{Letak Administratif Koridor Mertoyudan}

Secara administratif, kawasan koridor Mertoyudan terletak pada Kecamatan Mertoyudan serta melalui 3 (tiga) desa dan 1 (satu) kelurahan, meliputi Desa Banyurojo, Desa Mertoyudan, Desa Danurejo, dan Kelurahan Sumberrejo dengan luas sebesar 16,2 $\mathrm{km}^{2}$. Sesuai dengan peranannya sebagai pusat pelayanan kegiatan bagi wilayah-wilayah di sekitarnya, koridor Mertoyudan merupakan hirarki tertinggi di antara wilayah desa-desa lain di Kabupaten Magelang. Selain itu, koridor Mertoyudan juga memiliki kedudukan sebagai penyangga dari perkembangan Kota Magelang. Kondisi tersebut disebabkan karena letak administratif yang berbatasan langsung di sebelah selatan Kota Magelang sehingga terdampak langsung pertumbuhan kota yang bergerak ke arah selatan. Gambar 1 menggambarkan tentang posisi administrasi Koridor Mertoyudan.

\section{Penggunaan Lahan Kawasan Koridor Mertoyudan}

Penggunaan lahan eksisting di koridor Mertoyudan saat ini didominasi lahan terbangun dengan persentase sebesar $43 \%$ dari total luas wilayah. Kondisi demikian menunjukkan adanya perkembangan aktivtas perkotaan yang pesat di Koridor Mertoyudan akibat aglomerasi perkotaan yang titik tolaknya terjadi pada tahun 2010. Gambar 2 menggambarkan kondisi penggunaan lahan kawasan koridor Mertoyudan.

\section{Gambaran Aglomerasi Perkotaan di Kawasan Koridor Mertoyudan}

Aglomerasi perkotaan di koridor Mertoyudan pada awalnya dimulai dengan adanya pelebaran jalan arteri nasional yang menghubungkan Provinsi Jawa Tengah dengan DIY. Mengingat posisinya yang sangat strategis, Pemerintah Kabupaten Magelang akhirnya menetapkan koridor Mertoyudan sebagai salah satu kawasan cepat tumbuh di Kabupaten Magelang dan mengalokasikan ruang di Koridor Mertoyudan untuk kawasan bisnis. Perkembangan koridor Mertoyudan berkembang sangat pesat semenjak terjadinya aglomerasi. Hal ini dapat terlihat dari perkembangan lahan terbangun yang ada di sepanjang koridor. Sebelum terjadinya aglomerasi, lahan di sepanjang koridor Mertoyudan masih didominasi oleh rumah dan sawah. Adanya aglomerasi memberikan dampak yang cukup signifikan, dimana hingga saat ini terlihat konsentrasi bangunan dan aktivitas yang cukup tinggi. Dari sisi ekonomi, pendapatan masyarakat mengalami perubahan dengan adanya konsentrasi aktivitas perekonomian yang tinggi di koridor Mertoyudan. Sedangkan 
dari aspek sosial, fenomena yang paling jelas terlihat adalah terjadinya transformasi mata pencaharian masyarakat, dari semula masyarakat mayoritas bermata pencaharian di sektor primer (pertanian) menjadi beralih ke sektor tersier (perdagangan dan jasa).

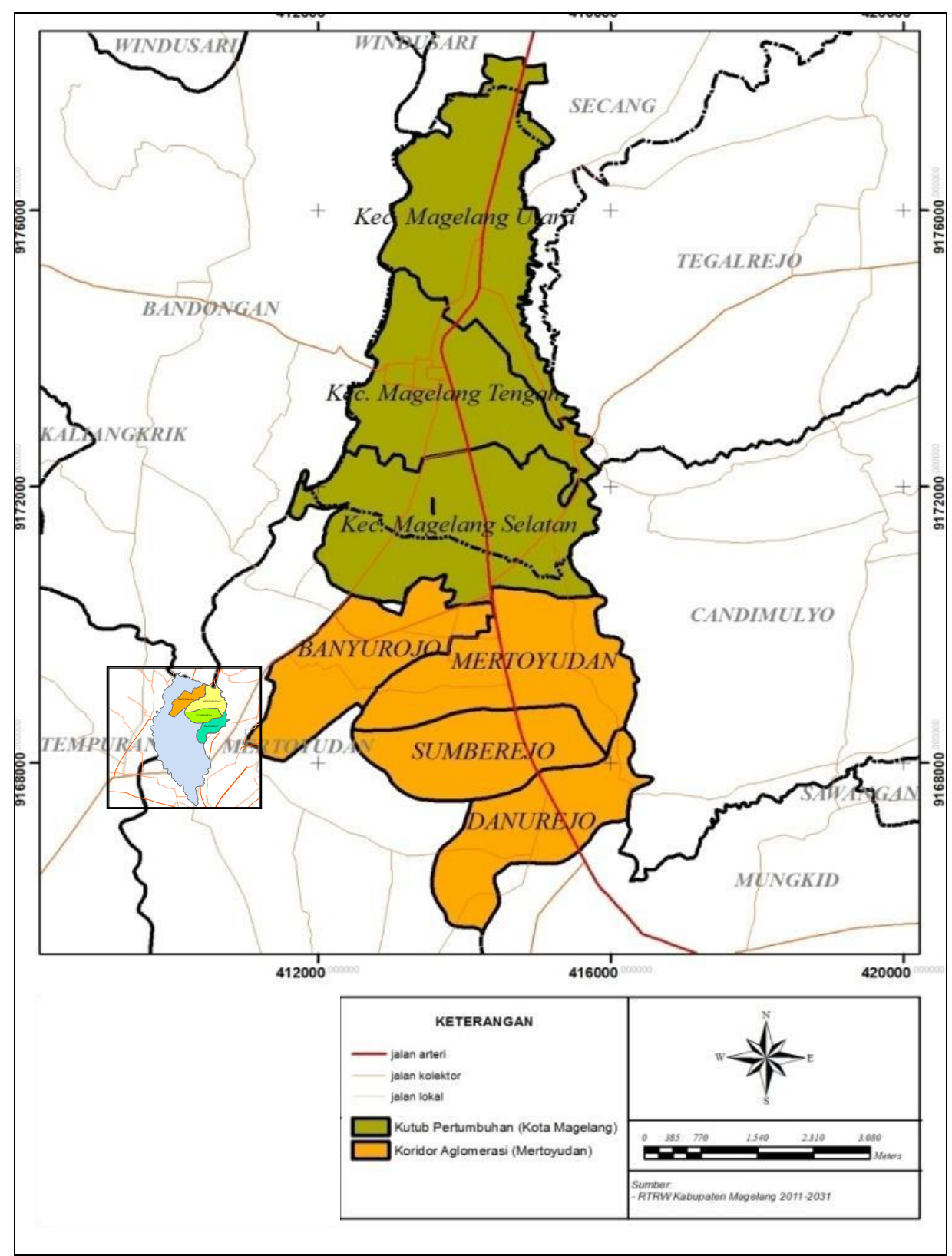

Sumber: RTRW Kabupaten Magelang Tahun 2011-2031 dan Modifikasi Google Earth, 2014

Gambar 1. Peta Administratif Kawasan Koridor Mertoyudan 


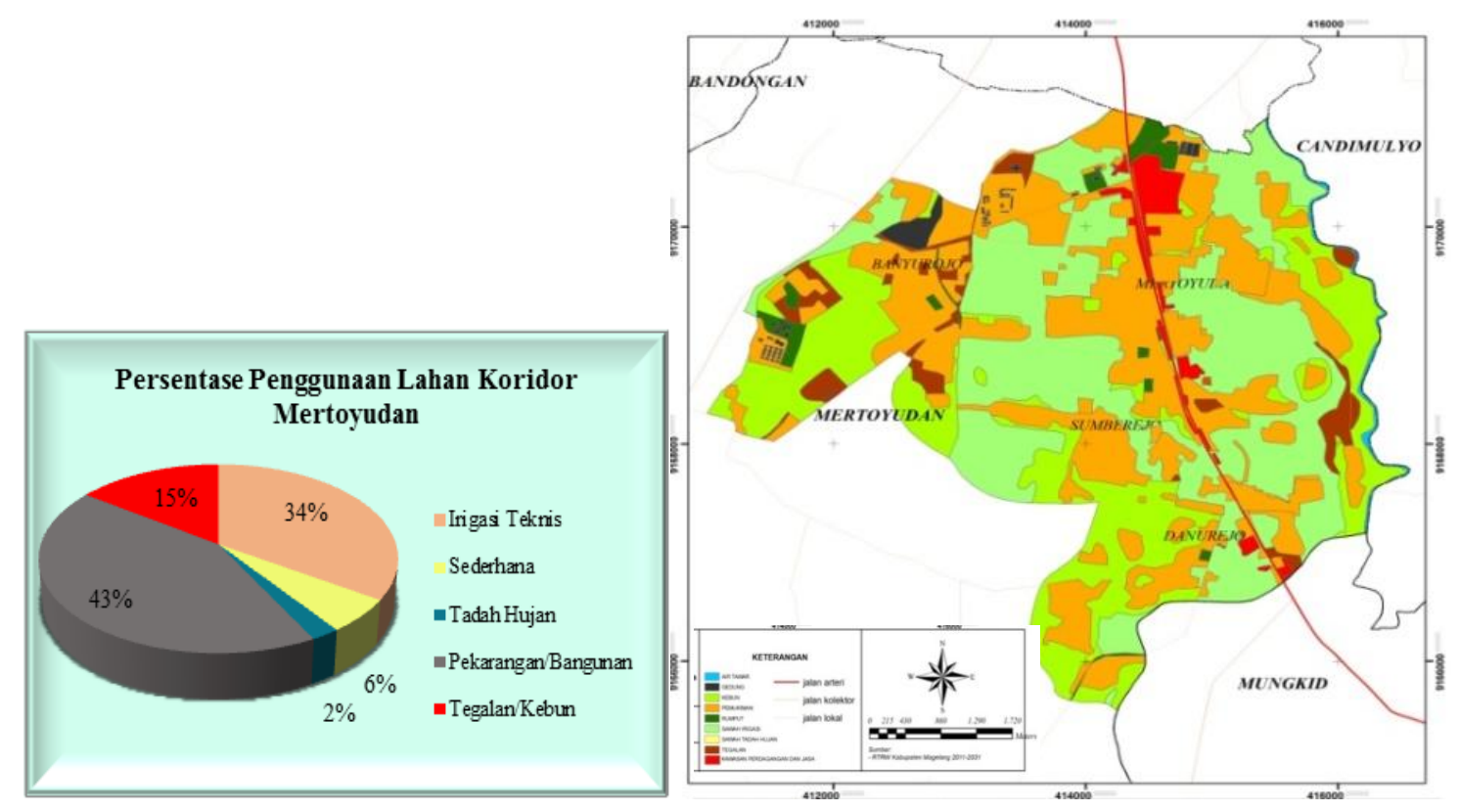

Sumber: Bappeda Kabupaten Magelang, 2011

Gambar 2. Kondisi Penggunaan Lahan Kawasan Koridor Mertoyudan

Perubahan Fisik Ruang dan Sosial Ekonomi Masyarakat sebagai Implikasi Aglomerasi Perkotaan di Koridor Mertoyudan

\section{Kronologi Aglomerasi Perkotaan di Koridor Mertoyudan}

Kota Magelang sebagai salah satu wilayah kota di provinsi Jawa Tengah terletak pada lokasi yang unik, yakni di tengah-tengah wilayah administrasi Kabupaten Magelang. Sebagai wilayah kota, Kota Magelang memiliki ciri khas yang hampir sama dengan kotakota lainnya di Jawa Tengah, yakni memiliki kepadatan penduduk yang tinggi dengan luas wilayah relatif kecil. Kepadatan penduduk di Kota Magelang yang tinggi menuntut pemenuhan pelayanan yang tinggi pula. Sedangkan dengan luas yang terbatas, Kota Magelang tidak dapat melayani sendiri kebutuhan wilayahnya sehingga perkembangan pemenuhan kebutuhan, terutama perumahan serta perdagangan dan jasa 'bergerak' ke arah selatan, yakni masuk ke wilayah Kabupaten Magelang karena letaknya yang berbatasan langsung. Hal ini menjadikan koridor Mertoyudan menangkap potensi pengembangan aktivitas ekonomi di sepanjang jalan, mulai dari Desa Mertoyudan, Banyurojo, Sumberrejo, hingga Danuharjo. Melihat embrio perkembangan kawasan Koridor Mertoyudan pada mulanya adalah pengaruh dari pergeseran perkembangan Kota Magelang, maka dapat dikatakan bahwa Kota Magelang merupakan kutub pertumbuhan dari aglomerasi perkotaan di koridor Mertoyudan. Gambar 3 menjelaskan kronologi aglomerasi perkotaan di Koridor Mertoyudan terhadap kawasan di sekitarnya. 


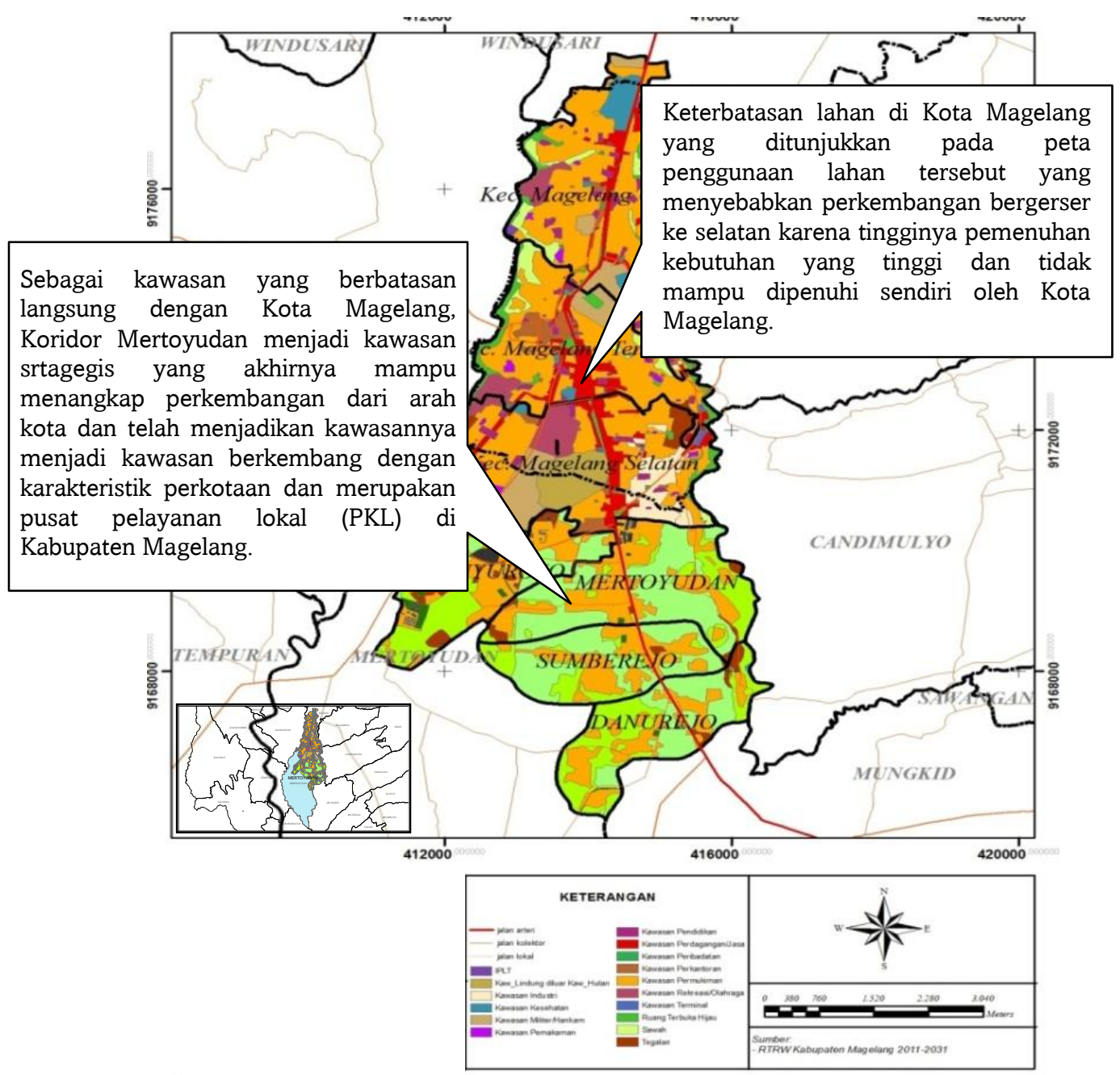

Gambar 3. Kronologi Aglomerasi Perkotaan di Koridor Mertoyudan

Adapun jika dikaitkan dengan masing-masing variabel penelitian, berikut penjelasan kronologi aglomerasi perkotaan di Koridor Mertoyudan:

a) Perubahan Fisik Ruang di Kawasan Koridor Mertoyudan

Dari hasil kuesioner kepada masyarakat di kawasan Koridor Mertoyudan, diketahui perubahan fisik ruang sangat tinggi. Sebesar $62 \%$ dari seluruh responden menyatakan adanya perubahan fisik ruang pada lahan yang ditinggalinya. Dari hasil penjaringan informasi yang lebih mendalam, perubahan fisik ruang yang dilakukan oleh masyarakat terhadap lahan yang ditinggali adalah karena adanya peluang ekonomi yang tinggi dari adanya jalan arteri nasional di koridor Mertoyudan dan juga karena faktor penarik lainnya. Arah perubahan fisik ruang di koridor Mertoyudan adalah sebagian besar menjadi lahan terbangun untuk aktivitas komersial atau dengan kata lain masyarakat melakukan pengembangan fungsi lahan yang semula hanya sebagai tempat tinggal menjadi lahan yang juga dapat mendatangkan nilai ekonomi.

b) Perubahan Mata Pencaharian Masyarakat di Kawasan Koridor Mertoyudan

Dari hasil survei primer diketahui bahwa perubahan mata pencaharian di koridor Mertoyudan sebagai akibat aglomerasi perkotaan cukup terlihat. Sebesar 53\% dari 


\section{Hubungan Perubahan Fisik Ruang dengan Kondisi Sosial Ekonomi Masyarakat...}

responden menyatakan beralih mata pencaharian setelah terjadinya aglomerasi perkotaan di koridor Mertoyudan dengan berbagai alasan. Di sisi lain, sebanyak 18\% dari seluruh responden memperoleh pekerjaan baru dengan meningkatnya aktivitas komersial di koridor Mertoyudan, dan 38\% lainnya merupakan masyarakat yang bertahan pada mata pencahariannya sejak sebelum terjadinya aglomerasi.

c) Perubahan Tingkat Penghasilan Masyarakat di Kawasan Koridor Mertoyudan

Hasil rekapitulasi kuesioner menunjukkan bahwa 98\% responden menyatakan adanya perubahan penghasilan dari sebelum aglomerasi dan setelah terjadinya aglomerasi. Namun dari $98 \%$ tersebut tidak semua mengalami perubahan yang positif. $72 \%$ responden menyatakan penghasilannya meningkat setelah peningkatan aktivitas di koridor Mertoyudan karena peluang ekonomi yang semakin tinggi, 14\% responden merupakan masyarakat yang baru bekerja di koridor Mertoyudan dan memperolah penghasilan baru pasca beraktivitas di koridor Mertoyudan, dan 12\% responden justru memperoleh penghasilan yang menurun dibandingkan sebelum aglomerasi.

d) Perubahan Frekuensi Mobilitas Masyarakat di Kawasan Koridor Mertoyudan

Hasil survei primer terhadap masyarakat terkait dengan frekuensi mobilitas menunjukkan bahwa sebesar $74 \%$ responden melakukan pergerakan yang lebih sering setelah terjadinya aglomerasi dibanding sebelum aglomerasi. Dari penggalian informasi lebih lanjut, diketahui beberapa faktor yang mempengaruhi peningkatan frekuensi pergerakan masyarakat di koridor Mertoyudan. Faktor pertama yang mempengaruhi tingginya mobilitas masyarakat adalah tingginya aksesibilitas yang ada karena pelebaran jalan arteri nasional hingga jalan lingkungan di kawasan permukiman. Dengan dukungan kondisi jaringan jalan yang memadai masyarakat dapat melakukan pergerakan lebih sering, baik untuk kepentingan beraktivitas rutin maupun tidak rutin.

e) Perubahan Frekuensi Interaksi Masyarakat di Kawasan Koridor Mertoyudan

Hasil survei primer menunjukkan bahwa persentase masyarakat yang frekuensi interaksi dengan sesama masyarakat lebih jarang sama dengan yang frekuensinya tetap. Sebesar 36\% masyarakat menyatakan frekuensi interaksi dengan tetangga lebih jarang karena aktivitas yang harus dijalani sehari-hari. Selain itu, ada faktor fisik juga yang mempengaruhi jarangnya interaksi masyarakat di sisi barat dan sisi timur koridor. Informasi ini diperoleh langsung dari masyarakat yang menyatakan bahwa pelebaran jalan justru menimbulkan resiko kecelakaan yang tinggi. Kondisi jalan yang semakin lebar mendorong pengguna kendaraan melaju dengan kecepatan tinggi sehingga tingkat kecelakaan meningkat. Hal tersebut yang menjadi hambatan interaksi masyarakat antar sisi jalan yang berseberangan. Di samping adanya frekuensi interaksi yang semakin jarang, 36\% masyarakat menyatakan frekuensi interaksi tidak mengalami perubahan. Diakui oleh masyarakat bahwa hubungan masyarakat masih cukup kuat meskipun kondisi fisik kawasan sudah banyak berubah. Berbeda dengan kondisi tersebut, sebanyak 28\% responden dapat melakukan interaksi sosial yang lebih sering dibandingkan sebelum adanya aglomerasi perkotaan. Kelompok ini adalah masyarakat yang kembali ke wilayah asalnya karena adanya kesempatan kerja di koridor Mertoyudan, yang sebelumnya bekerja di luar wilayah. Dengan adanya kondisi tersebut, keterkaitan antara terjadinya aglomerasi perkotaan di koridor Mertoyudan dengan perubahan frekuensi interaksi belum dapat diidentifikasi. Namun untuk lebih jelasnya akan dilakukan analisis statistik untuk melihat secara lebih jelas hubungan antara perubahan fisik ruang yang menandai aglomerasi perkotaan di koridor Mertoyudan dengan perubahan sosial dilihat dari perubahan frekuensi interaksi masyarakat. 


\section{Analisis Hubungan Perubahan Fisik Ruang dengan Mata Pencaharian Masyarakat di Kawasan Koridor Mertoyudan}

Nilai Asymp. Sig. dari hubungan antara perubahan fisik dengan mata pencaharian masyarakat sebesar 0,000 atau kurang dari 0,05 yang berarti bahwa $\mathrm{H}_{0}$ ditolak. Dengan demikian, menunjukkan bahwa ada hubungan antara perubahan fisik ruang dengan perubahan mata pencaharian masyarakat di koridor Mertoyudan akibat aglomerasi perkotaan. Secara lebih rinci, nilai Chi-Square test dari analisis Crosstab terjabarkan di Tabel 1.

Tabel 1. Chi-Square Tests Hubungan Perubahan Perubahan Fisik Ruang dengan Mata Pencaharian

\begin{tabular}{lccc}
\hline & Value & df & Asymp. Sig. (2-sided) \\
\hline Pearson Chi-Square & $32,525^{(\mathrm{a})}$ & 6 &, 000 \\
Likelihood Ratio & 41,882 & 6 &, 000 \\
Linear-by-Linear Association & 24,518 & 1 &, 000 \\
\hline
\end{tabular}

Nilai signifikansi pada kondisi perubahan mata pencaharian merupakan variabel terikat yang dipengaruhi oleh perubahan fisik ruang sebagai varaibel bebas adalah sebesar 0,100 (lihat Tabel 2). Nilai signifikansi tersebut lebih dari 0,05 yang berarti bahwa perubahan fisik ruang sebagai variabel bebas mampu memprediksi perubahan mata pencaharian secara signifikan. Jika dikaitkan dengan kondisi nyata di wilayah studi, peningkatan aktivitas ekonomi yang ditandai dengan perubahan fungsi lahan menyebabkan tingginya masyarakat yang beralih mata pencaharian ke arah sektor sekunder yang didominasi oleh sektor perdagangan.

Tabel 2. Directional Measures Hubungan Perubahan Fisik Ruang dengan Mata Pencaharian

\begin{tabular}{|c|c|c|c|c|c|c|}
\hline & & & Value & $\begin{array}{c}\text { Asymp. Std. } \\
\text { Error }^{(a)}\end{array}$ & $\begin{array}{c}\underset{\mathbf{T}^{(b)}}{\operatorname{Approx} .} \\
.\end{array}$ & $\begin{array}{c}\text { Approx. } \\
\text { Sig. }\end{array}$ \\
\hline \multirow{10}{*}{$\begin{array}{l}\text { Nominal } \\
\text { by } \\
\text { Nominal }\end{array}$} & \multirow[t]{4}{*}{ Lambda } & Symmetric & ,327 & ,093 & 2,950 & ,003 \\
\hline & & Per MataPencaharian & & & & \\
\hline & & Dependent & ,286 &, 151 & 1,646 & , 100 \\
\hline & & Per Fisik Dependent & 355 & ,093 & 3,382 & ,001 \\
\hline & \multirow{6}{*}{$\begin{array}{l}\text { Goodman } \\
\text { and } \\
\text { Kruskal tau } \\
\text { Uncertainty } \\
\text { Coefficient }\end{array}$} & Per MataPencaharian & 389 & 054 & &, $000^{(\mathrm{c})}$ \\
\hline & & Per Fisik Dependent & 252 & , 062 & & $.000^{(\mathrm{c})}$ \\
\hline & & Symmetric & ,364 &, 052 & 6,969 &, $000^{(\mathrm{d})}$ \\
\hline & & Per MataPencaharian & & & & $000^{(\mathrm{d})}$ \\
\hline & & Dependent & ,437 & ,061 & 6,969 &, 000 \\
\hline & & Per Fisik Dependent & 312 & ,048 & 6,969 &, $000^{(\mathrm{d})}$ \\
\hline
\end{tabular}

Dari hasil analisis yang telah dilakukan (lihat Tabel 3), nilai Phi, Cramer's V, dan Contingency Coefficient adalah 0,807, 0,570, dan 0,628. Ini menunjukkan bahwa ketiga nilai tersebut memiliki hubungan kuat antara perubahan fisik ruang dengan perubahan mata pencaharian karena nilai korelasi di atas 0,5 dan mendekati angka 1 . Koefisien positif dari masing-masing nilai korelasi menunjukkan adanya hubungan searah (positif) antara perubahan fisik ruang dengan perubahan mata pencaharian, dimana semakin tinggi perubahan fisik ruang (fungsi lahan yang mengarah pada fungsi komersial) maka semakin tinggi juga jumlah masyarakat yang beralih mata pencaharian di koridor Mertoyudan. 
Hubungan Perubahan Fisik Ruang dengan Kondisi Sosial Ekonomi Masyarakat...

Tabel 3. Symmetric Measures Hubungan Perubahan Fisik Ruang dengan Mata Pencaharian

\begin{tabular}{|c|c|c|c|c|c|c|}
\hline & & & Value & $\begin{array}{c}\text { Asymp. Std. } \\
\text { Error }^{(\mathbf{a})}\end{array}$ & $\begin{array}{c}\text { Approx. } \\
\mathbf{T}^{(\mathbf{b})}\end{array}$ & $\begin{array}{c}\text { Approx. } \\
\text { Sig. }\end{array}$ \\
\hline \multirow{3}{*}{$\begin{array}{l}\text { Nominal } \\
\text { Nominal }\end{array}$} & \multirow{3}{*}{ by } & Phi & 807 & & & ,000 \\
\hline & & Cramer's V &, 570 & & & 000 \\
\hline & & Contingency Coefficient & 628 & & & ,000 \\
\hline $\begin{array}{l}\text { Interval } \\
\text { Interval }\end{array}$ & by & Pearson's R & ,707 & ,090 & 6,993 &, $000^{(\mathrm{c})}$ \\
\hline $\begin{array}{l}\text { Ordinal } \\
\text { Ordinal }\end{array}$ & by & Spearman Correlation & ,727 & ,085 & 7,326 &, $000^{(\mathrm{c})}$ \\
\hline
\end{tabular}

\section{Analisis Hubungan Perubahan Fisik Ruang dengan Tingkat Penghasilan Masyarakat di Kawasan Koridor Mertoyudan}

Uji Chi-Square menunjukkan nilai signifikansi untuk uji hubungan antara perubahan fisik ruang dengan perubahan penghasilan masyarakat adalah sebesar 0,002 atau kurang dari 0,5 yang berarti bahwa ada hubungan antara perubahan fisik ruang dengan perubahan mata pencaharian masyarakat di koridor Mertoyudan akibat aglomerasi perkotaan yang terjadi. Hasil Chi-Square tes terlihat di Tabel 4.

Tabel 4. Chi-Square Tests Hubungan Perubahan Fisik Ruang dengan Tingkat Penghasilan

\begin{tabular}{lccc}
\hline & Value & df & Asymp. Sig. (2-sided) \\
\hline Pearson Chi-Square & $25,642^{(\mathrm{a})}$ & 9 &, 002 \\
Likelihood Ratio & 27,676 & 9 &, 001 \\
Linear-by-Linear Association & 17,714 & 1 &, 000 \\
\hline
\end{tabular}

Aglomerasi perkotaan yang terjadi di koridor Mertoyudan yang menyebabkan perubahan aktivitas dan ruang ke arah urban telah membawa perubahan nilai ekonomi masyarakat yang diukur dari tingkat penghasilan. Nilai signifikansi pada posisi perubahan fisik sebagai variabel bebas dan perubahan tingkat penghasilan sebagai variabel terikat adalah sebesar 0,086 sehingga menunjukkan bahwa perubahan fisik ruang sebagai variabel bebas dapat memprediksi perubahan tingkat penghasilan yang merupakan variabel terikat (lihat Tabel 5). Kondisi ini menggambarkan bahwa perubahan fisik ruang mampu memberikan pengaruh terhadap perubahan tingkat penghasilan masyarakat.

Tabel 5. Directional Measures Hubungan Perubahan Fisik Ruang dengan Tingkat Penghasilan

\begin{tabular}{|c|c|c|c|c|c|c|}
\hline & & & Value & $\begin{array}{c}\text { Asymp. Std. } \\
\text { Error }^{(a)}\end{array}$ & $\begin{array}{c}\text { Approx. } \\
\mathbf{T}^{(\mathbf{b})}\end{array}$ & $\begin{array}{c}\text { Approx. } \\
\text { Sig. }\end{array}$ \\
\hline \multirow{8}{*}{$\begin{array}{l}\text { Nominal } \\
\text { by } \\
\text { Nominal }\end{array}$} & \multirow[t]{3}{*}{ Lambda } & Symmetric & ,241 & ,086 & 2,553 & ,011 \\
\hline & & $\begin{array}{l}\text { Per Penghasilan } \\
\text { Dependent }\end{array}$ & , 185 & , 100 & 1,715 & ,086 \\
\hline & & Per Fisik Dependent & 290 & 090 & 2,939 & 003 \\
\hline & \multirow{5}{*}{$\begin{array}{l}\text { Goodman } \\
\text { and Kruskal } \\
\text { tau } \\
\text { Uncertainty } \\
\text { Coefficient }\end{array}$} & $\begin{array}{l}\text { Per Penghasilan } \\
\text { Dependent }\end{array}$ &, 153 &, 052 & &, $008^{(\mathrm{c})}$ \\
\hline & & Per Fisik Dependent &, 190 &, 051 & &, $001^{(\mathrm{c})}$ \\
\hline & & Symmetric & 217 & 057 & 3,636 &, $001^{(\mathrm{d})}$ \\
\hline & & $\begin{array}{l}\text { Per Penghasilan } \\
\text { Dependent }\end{array}$ & ,229 &, 056 & 3,636 &, $001^{(\mathrm{d})}$ \\
\hline & & Per Fisik Dependent & ,206 & 057 & 3,636 &, $001^{(\mathrm{d})}$ \\
\hline
\end{tabular}


Value pada Phi, Cramer's V, dan Contingency Coefficient masing-masing adalah 0,716; 0,413; dan 0,582 (lihat Tabel 6). Dengan demikian maka dapat disimpulkan adanya hubungan yang kuat antara variabel perubahan fisik ruang dengan perubahan tingkat penghasilan masyarakat koridor Mertoyudan akibat terjadinya aglomerasi perkotaan. Selain itu, dengan melihat nilai korelasi dengan koefisien positif tersebut menggambarkan adanya hubungan searah (sebanding) antara perubahan fisik ruang dengan perubahan tingkat penghasilan masyarakat.

Tabel 6. Symmetric Measures Hubungan Perubahan Fisik Ruang dengan Tingkat Penghasilan

\begin{tabular}{|c|c|c|c|c|c|c|}
\hline & & & Value & $\begin{array}{c}\text { Asymp. Std. } \\
\text { Error }^{(\mathbf{a})}\end{array}$ & $\underset{\mathbf{T}^{(\mathbf{b})}}{\text { Approx. }}$ & $\begin{array}{c}\text { Approx. } \\
\text { Sig. }\end{array}$ \\
\hline \multirow{3}{*}{$\begin{array}{l}\text { Nominal } \\
\text { Nominal }\end{array}$} & \multirow{3}{*}{ by } & Phi & ,716 & & &, 002 \\
\hline & & Cramer's V & 413 & & & 002 \\
\hline & & Contingency Coefficient &, 582 & & & 002 \\
\hline $\begin{array}{l}\text { Interval } \\
\text { Interval }\end{array}$ & by & Pearson's R &, 601 & ,085 & &, $000^{(\mathrm{c})}$ \\
\hline $\begin{array}{l}\text { Ordinal } \\
\text { Ordinal }\end{array}$ & by & Spearman Correlation &, 578 & , 100 & &, $000^{(c)}$ \\
\hline
\end{tabular}

\section{Analisis Hubungan Perubahan Fisik Ruang dengan Frekuensi Mobilitas Masyarakat di Kawasan Koridor Mertoyudan}

Dari tabel Chi-Square (Tabel 7), diketahui bahwa nilai signifikansi sebesar 0,000 dan menunjukkan bahwa ada hubungan yang signifikan antara perubahan fisik ruang dengan perubahan frekuensi mobilitas masyarakat di koridor Mertoyudan.

Tabel 7. Chi-Square Tests Hubungan Perubahan Fisik Ruang dengan Frekuensi Mobilitas

\begin{tabular}{lccc}
\hline & Value & df & Asymp. Sig. (2-sided) \\
\hline Pearson Chi-Square & $27,997^{(\mathrm{a})}$ & 6 &, 000 \\
Likelihood Ratio & 34,123 & 6 &, 000 \\
Linear-by-Linear Association & 23,768 & 1 &, 000 \\
\hline
\end{tabular}

Variabel perubahan fisik ruang diposisikan sebagai variabel bebas dan variabel perubahan frekuensi mobilitas masyarakat sebagai variabel terikat menghasilkan nilai signifikansi sebesar 0,062 (lihat Tabel 8). Nilai signifikansi tersebut lebih besar dari 0,05 yang berarti bahwa perubahan fisik ruang sebagai variabel bebas dapat memprediksi perubahan frekuensi mobilitas masyarakat yang merupakan variabel terikat. Dengan kata lain, perubahan fisik ruang di koridor Mertoyudan dapat mempengaruhi perubahan frekuensi mobiltas masyarakat.

Tabel 8. Directional Measures Hubungan Perubahan Fisik Ruang dengan Frekuensi Mobilitas

\begin{tabular}{|c|c|c|c|c|c|c|}
\hline & & & Value & $\begin{array}{c}\text { Asymp. Std. } \\
\text { Error }^{(a)}\end{array}$ & $\begin{array}{c}\text { Approx. } \\
\mathbf{T}^{(\mathbf{b})}\end{array}$ & $\begin{array}{c}\text { Approx. } \\
\text { Sig. }\end{array}$ \\
\hline \multirow{4}{*}{$\begin{array}{l}\text { Nominal } \\
\text { by } \\
\text { Nominal }\end{array}$} & \multirow[t]{3}{*}{ Lambda } & Symmetric & ,302 & ,101 & 2,566 & , 010 \\
\hline & & $\begin{array}{l}\text { Per Mobilitas } \\
\text { Dependent }\end{array}$ & ,318 & 145 & 1,869 &, 062 \\
\hline & & Per Fisik Dependent & 290 &, 105 & 2,460 & 014 \\
\hline & $\begin{array}{l}\text { Goodman } \\
\text { and Kruskal }\end{array}$ & $\begin{array}{l}\text { Per Mobilitas } \\
\text { Dependent }\end{array}$ & ,318 & 072 & &, $000^{(\mathrm{c})}$ \\
\hline
\end{tabular}




\begin{tabular}{llcccc}
\hline & Value & $\begin{array}{c}\text { Asymp. Std. } \\
\text { Error }^{(\mathbf{a})}\end{array}$ & $\begin{array}{c}\text { Approx. } \\
\mathbf{T}^{(\mathbf{b})}\end{array}$ & $\begin{array}{c}\text { Approx. } \\
\text { Sig. }\end{array}$ \\
\hline tau & Per Fisik Dependent &, 206 &, 053 & &, $000^{(\mathbf{c})}$ \\
Uncertainty & Symmetric &, 299 &, 055 & 5,211 &, $000^{(\mathrm{d})}$ \\
Coefficient & Per Mobilitas &, 362 &, 064 & 5,211 &, $000^{(\mathrm{d})}$ \\
& Dependent &, 255 &, 050 & 5,211 &, $000^{(\mathrm{d})}$ \\
\hline
\end{tabular}

Value pada Phi, Cramer's V, dan Contingency Coefficient menunjukkan korelasi sebesar 0,748; 0,529; dan 0,599 (lihat Tabel 9). Nilai korelasi dari ketiganya lebih dari 0,5 dan mendekati 1 sehingga menunjukkan adanya hubungan yang kuat antara perubahan fisik ruang dengan perubahan frekuensi mobilitas masyarakat di koridor Mertoyudan. Koefisien korelasi yang bernilai positif menunjukkan hubungan searah (berbanding lurus) antara perubahan fisik ruang dengn perubahan frekuensi mobilitas masyarakat.

Tabel 9. Symmetric Measures Hubungan Perubahan Fisik Ruang dengan Frekuensi Mobilitas

\begin{tabular}{|c|c|c|c|c|c|c|}
\hline & & & Value & $\begin{array}{c}\text { Asymp. Std. } \\
\text { Error }^{(\mathbf{a})}\end{array}$ & $\underset{\mathbf{T}^{(\mathbf{b})}}{\operatorname{Approx} .}$ & $\begin{array}{c}\text { Approx. } \\
\text { Sig. }\end{array}$ \\
\hline \multirow{3}{*}{$\begin{array}{l}\text { Nominal } \\
\text { Nominal }\end{array}$} & \multirow{3}{*}{ by } & Phi & ,748 & & & 000 \\
\hline & & Cramer's V &, 529 & & & 000 \\
\hline & & Contingency Coefficient &, 599 & & & 000 \\
\hline $\begin{array}{l}\text { Interval } \\
\text { Interval }\end{array}$ & by & Pearson's R & ,696 & ,067 & 6,724 &, $000^{(\mathrm{c})}$ \\
\hline $\begin{array}{l}\text { Ordinal } \\
\text { Ordinal }\end{array}$ & by & Spearman Correlation & 679 & ,085 & 6,411 &, $000^{(\mathrm{c})}$ \\
\hline
\end{tabular}

\section{Analisis Hubungan Perubahan Fisik Ruang dengan Frekuensi Interaksi Masyarakat di Kawasan Koridor Mertoyudan}

Nilai signifikansi untuk hubungan perubahan fisik ruang dengan perubahan frekuensi masyarakat di koridor Mertoyudan adalah sebesar 0,070. Berbeda dengan parameter lainnya, dari nilai signifikansi yang lebih besar dari 0,05 tersebut menunjukkan bahwa tidak ada hubungan antara perubahan fisik ruang dengan perubahan frekuensi interaksi sosial masyarakat. Hasil uji Chi-Square hubungan perubahan fisik ruang dengan frekuensi interaksi terjelaskan di Tabel 10.

Tabel 10. Chi-Square Tests Hubungan Perubahan Fisik Ruang dengan Frekuensi Interaksi

\begin{tabular}{lccc}
\hline & Value & df & Asymp. Sig. (2-sided) \\
\hline Pearson Chi-Square & $11,676^{(\mathrm{a})}$ & 6 &, 070 \\
Likelihood Ratio & 13,099 & 6 &, 041 \\
Linear-by-Linear Association & 2,095 & 1 &, 148 \\
\hline
\end{tabular}

Nilai Phi, Cramer's V, dan Contingency Coefficient sebesar 0,483; 0,342; dan 0,435 (lihat Tabel 11) menunjukkan korelasi yang lemah antara perubahan fisik ruang dengan perubahan frekuensi interaksi sosial masyarakat di koridor Mertoyudan. Jika di-cross-check dengan kondisi di lapangan, meskipun telah terjadi pekembangan dan perubahan aktivitas yang mengarah ke karakteristik perkotaan, tetapi interaksi masyarakat masih cukup kuat. Tingginya aktivitas ekonomi dan aktivitas perkotaan lainnya tidak menyebabkan interaksi masyarakat menjadi lebih jarang. Kondisi interaksi masyarakat masih bersifat rural. Oleh karena itu, aglomerasi perkotaan yang terjadi di koridor Mertoyudan tidak memberikan 
implikasi yang berarti bagi interaksi dan hubungan antar masyarakat yang tinggal di kawasan tersebut.

Tabel 11. Symmetric Measures Hubungan Perubahan Fisik Ruang dengan Frekuensi Interaksi

\begin{tabular}{|c|c|c|c|c|c|c|}
\hline & & & Value & $\underset{\text { Error }^{(a)}}{\text { Asymp. Std. }}$ & $\underset{\mathbf{T}^{(\mathbf{b})}}{\operatorname{Approx}}$ & $\begin{array}{c}\text { Approx. } \\
\text { Sig. }\end{array}$ \\
\hline \multirow{3}{*}{$\begin{array}{l}\text { Nominal } \\
\text { Nominal }\end{array}$} & \multirow{3}{*}{ by } & Phi & ,483 & & & ,070 \\
\hline & & Cramer's V &, 342 & & & 070 \\
\hline & & Contingency Coefficient & ,435 & & & ,070 \\
\hline $\begin{array}{l}\text { Interval } \\
\text { Interval }\end{array}$ & by & Pearson's R &,- 207 & , 142 & $-1,464$ &, $150^{(\mathrm{c})}$ \\
\hline $\begin{array}{l}\text { Ordinal } \\
\text { Ordinal }\end{array}$ & by & Spearman Correlation &,- 212 & 141 & $-1,506$ &, $139^{(\mathrm{c})}$ \\
\hline
\end{tabular}

Pola Hubungan Perubahan Fisik Ruang dengan Kondisi Sosial Ekonomi Masyarakat di Kawasan Koridor Aglomerasi Mertoyudan, Kabupaten Magelang

Dengan telah dilakukannya analisis tabulasi silang (crosstab) menggunakan aplikasi SPSS versi 13.0, berikut bentuk hubungan dari perubahan fisik ruang dengan perubahan sosial ekonomi masyarakat sebagai implikasi aglomerasi perkotaan di koridor Mertoyudan:

- Ada hubungan nyata yang signifikan antara perubahan fisik ruang dengan mata pencaharian masyarakat, dengan fisik ruang sebagai variabel bebas yang mempengaruhi perubahan mata pencaharian masyarakat. Nilai korelasi di atas 0,5 menunjukkan bahwa antara kedua variabel memiliki hubungan yang kuat.

- Perubahan fisik ruang di koridor Mertoyudan mampu memprediksi perubahan penghasilan masyarakat dan kedua variabel tersebut memiliki hubungan yang nyata dan signifikan. Nilai korelasi yang lebih dari 0,5 menunjukkan adanya keterkaitan yang kuat antara perubahan fisik ruang dengan perubahan penghasilan masyarakat di koridor Mertoyudan.

- $\quad$ Terdapat hubungan yang signifikan antara perubahan fisik ruang dengan frekuensi mobilitas masyarakat akibat aglomerasi perkotaan. Dengan nilai korelasi lebih dari 0,5 menunjukkan hubungan yang kuat antara perubahan fisik ruang dengan frekuensi mobilitas masyarakat.

- Dengan perubahan jarak lokasi aktivitas, perubahan ruang juga memiliki hubungan signifikan yang kuat. Dalam hubungannya, perubahan jarak lokasi aktivitas mampu memprediksi terjadinya perubahan fisik ruang di koridor Mertoyudan.

- Nilai signifikansi menunjukkan bahwa tidak ada hubungan nyata dan signifikan antara perubanhan fisik ruang dengan frekuensi interaksi masyarakat di koridor Mertoyudan. Jadi perkembangan aktivitas dan fisik mengarah ke urban tetapi kondisi sosial masyarakat masih cenderung rural.

Gambar 4 berikut menjelaskan mengenai model hubungan perubahan fisik ruang dan sosial ekonomi akibat aglomerasi perkotaan di koridor Mertoyudan: 


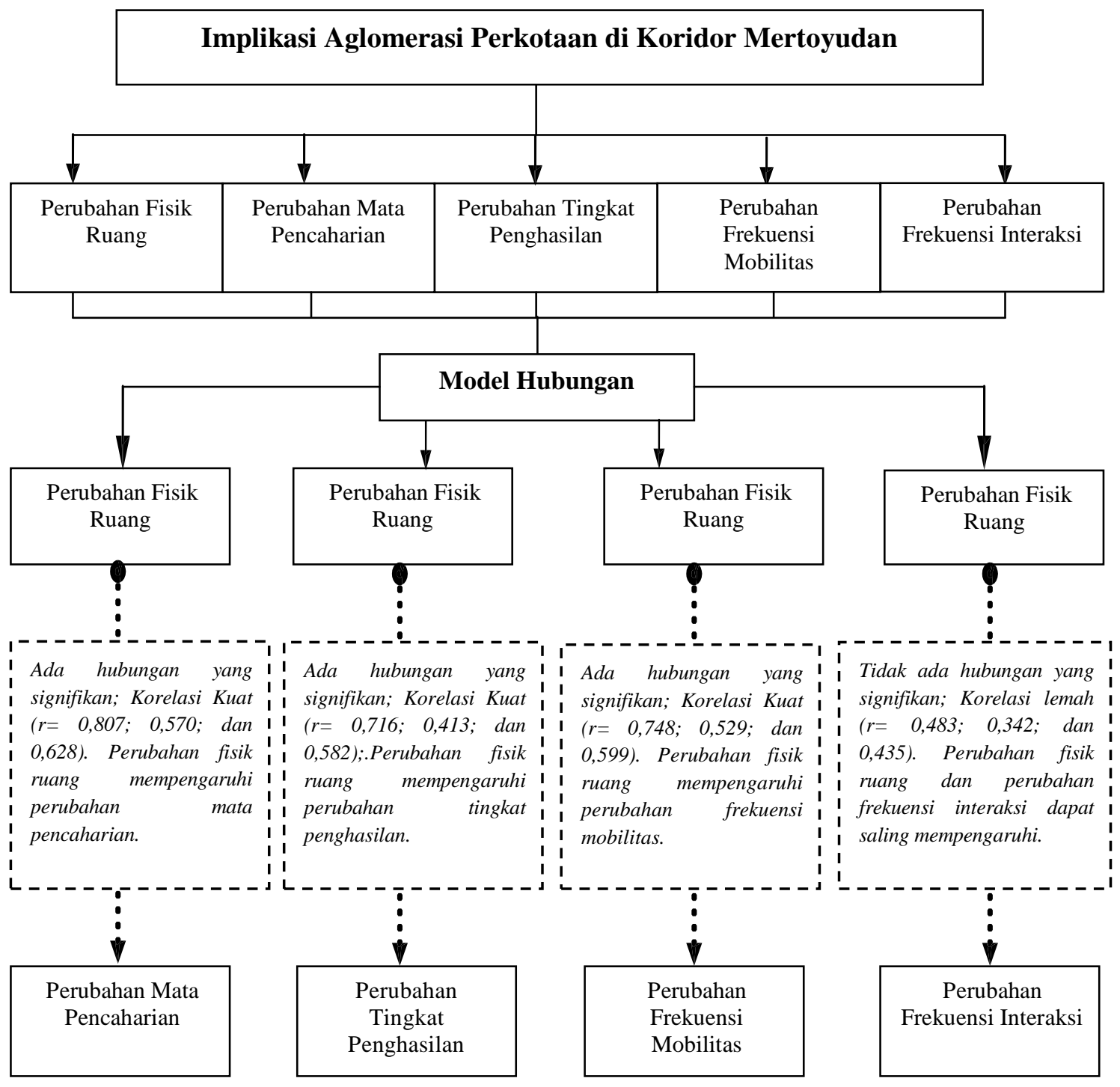

Keterangan: Variabel Bebas (Independent)

Variabel Terikat (Dependent)

\section{Gambar 4. Model Hubungan Perubahan Fisik Ruang dan Sosial Ekonomi Akibat Aglomerasi Perkotaan di Koridor Mertoyudan}

Perubahan guna lahan merupakan suatu hal yang menjadi ciri dari perkembangan kota. Terkait dengan fenomena aglomerasi, perubahan guna lahan yang banyak terjadi adalah konversi lahan pertanian yang berubah menjadi fungsi nonkomersial. Untuk aglomerasi di sepanjang koridor utama Mertoyudan, konversi lahan banyak terjadi karena nilai lahan yang sangat tinggi dan kurang menguntungkan ketika hanya dimanfaatkan sebagai fungsi pertanian. Konversi lahan yang terjadi akibat aglomerasi biasanya terjadi secara drastis dalam kurun waktu yang tidak panjang. Hal ini sejalan dengan temuan Faizah dan Hendarto (2013) mengenai aglomerasi perkotaan Yogyakarta bahwa adanya pembangunan fasilitas perekonomian di sepanjang jalan kawasan yang teraglomerasi berdampak pada nilai lahan yang tinggi sehingga banyak masyarakat yang menjual permukiman untuk dialihfungsikan menjadi kawasan perdagangan dan jasa yang lebih bernilai ekonomis dan dapat digunakan untuk tujuan investasi. 
Konversi lahan pertanian ini pada akhirnya memberikan dampak, baik terhadap masyarakat, aktivitas, maupun lingkungan. Dalam aglomerasi di koridor Mertoyudan, konversi lahan menyebabkan terjadinya transformasi mata pencaharian masyarakat, meningkatnya pendapatan secara ekonomi, masuknya penduduk pendatang, serta berkurangnya ruang hijau. Aglomerasi yang dibarengi dengan konversi lahan serta menyebabkan tranformasi mata pencaharian masyarakat dari sektor pertanian menjadi sektor nonpertanian pada umumnya menyebabkan pendapatan masyarakat meningkat. Namun demikian, aglomerasi menyebabkan penurunan kondisi lingkungan yang ditandai dengan berkurangnya ruang terbuka hijau. Serupa dengan temuan bahwa aglomerasi berdampak pada penurunan kondisi lingkungan akibat adanya urbanisasi yang mengubah guna lahan (Poyil \& Misra, 2015).

Dalam kaitannya dengan aglomerasi, perubahan ekonomi dapat dilihat dari strukturnya. Perubahan struktur ekonomi pada dasarnya adalah melihat pergeseran struktur ekonomi yang mengalami pergeseran dari yang semula didominasi oleh sektor primer, seperti pertanian ke sektor-sektor nonprimer, seperti industri, perdagangan dan jasa. Hal ini menunjukkan bahwa dampak aglomerasi secara ekonomi dapat meningkatkan kesejahteraan penduduk sekitar karena peralihan mata pencaharian ke arah sektor tersier yang lebih menjanjikan.

Proses aglomerasi juga berdampak pada dinamika sosial. Dinamika sosial berarti bahwa manusia dan masyarakat selalu berkembang serta mengalami perubahan. Perubahan akan selalu ada dalam setiap kelompok sosial, baik mengalami perubahan secara lambat maupun mengalami perubahan secara cepat (Soekanto, 2006: 146). Perubahan sosial secara umum dapat diartikan sebagai suatu proses pergeseran atau berubahnya struktur atau tatanan didalam masyarakat, meliputi pola pikir yang lebih inovatif, sikap, serta kehidupan sosialnya untuk mendapatkan penghidupan yang lebih bermartabat. Namun demikian, aglomerasi tidak berdampak pada karakteristik interaksi sosial masyarakat di sekitar koridor Mertoyudan.

Aglomerasi mampu memacu pertumbuhan fisik dan ekonomi perkotaan karena ada perbedaan ukuran kota yang mendorong kota untuk dapat saling berbagi sumber daya spesifik yang dimiliki termasuk di dalamnya infrastruktur dan berbagai fasilitas publik (Cruz Villamil, 2010). Ini menunjukkan bahwa masih ada saling ketergantungan antar kawasan yang beraglomerasi. Hal ini akan meningkatkan frekuensi mobilitas masyarakat akibat adanya ketergantungan kawasan sekitar Mertoyudan dengan pusat pertumbuhan, yaitu Kota Magelang. Hal ini sesuai dengan pendapat Gan, Ping-yu, dan Bin, 2006 serta Chuanglin, Jitao, dan Dunjiang, 2007 bahwa keberadaan jaringan transportasi berperan penting dalam aglomerasi perkotaan untuk menunjang pergerakan dan mempermudah pasar.

\section{Kesimpulan}

Koridor Mertoyudan merupakan salah satu kawasan yang tumbuh dan berkembang dari aglomerasi perkotaan. Hal tersebut dibuktikan dari awal perkembangan kawasan yang dimulai dari pengaruh pergeseran perkembangan Kota Magelang dan pelebaran jalan arteri nasional Magelang-DIY yang menyebabkan aktivitas ekonomi tumbuh dan mengelompok dan menggunakan aksesibilitas serta tenaga kerja lokal sebagai resource yang sama. Aglomerasi perkotaan tersebut memberikan implikasi terhadap perubahan fisik ruang (penggunaan dan fungsi lahan), perubahan mata pencaharian masyarakat, tingkat penghasilan masyarakat, frekuensi mobilitas, dan frekuensi interaksi. Tingginya pengaruh aglomerasi terhadap perkembangan fisik kawasan dapat terlihat dari tingginya konsentrasi lahan terbangun di sepanjang koridor Mertoyudan. Perbedaan perkembangan fisik yang terlihat adalah pada kawasan sepanjang koridor Mertoyudan didominasi pemanfaatan 


\section{Hubungan Perubahan Fisik Ruang dengan Kondisi Sosial Ekonomi Masyarakat...}

lahan sebagai perdagangan dan jasa serta permukiman penunjang aktivitas tersebut. Sedangkan di bagian dalam, pemanfaatan lahan didominasi lahan pertanian dan kawasan permukiman dengan kepadatan rendah.

Perubahan mata pencaharian yang terjadi di kawasan koridor Mertoyudan diyakini kuat karena implikasi aglomerasi perkotaan karena perubahan mata pencaharian seiring dengan peningkatan aktivitas ekonomi nonagraris yang meningkat sejak pelebaran jalan arteri nasional Kabupaten Magelang tahun 2010. Perubahan tingkat penghasilan masyarakat pada umumnya memang terkait dengan pengaruh inflasi ekonomi. Namun dalam penelitian ini, dapat dibuktikan secara kuat bahwa aglomerasi perkotaan memang memberikan implikasi terhadap perubahan tingkat penghasilan masyarakat karena kelompok responden yang menyatakan tingkat penghasilannya meningkat adalah sebagian besar masyarakat yang bekerja di kawasan koridor Mertoyudan. Dari hasil analisis yang telah dilakukan, dapat disimpulkan secara garis besar ada hubungan yang signifikan antara perubahan fisik ruang dengan kondisi sosial ekonomi masyarakat akibat aglomerasi di koridor Mertoyudan. Namun aglomerasi perkotaan secara signifikan tidak mempengaruhi frekuensi interaksi masyarakat. Terkait dengan ketidaksesuaian terhadap teori tersebut, hal yang dapat ditarik adalah karena aglomerasi perkotaan yang terjadi di kawasan koridor Mertoyudan masih dalam fase awal sehingga belum mempengaruhi interaksi masyarakat secara signifikan.

\section{Daftar Pustaka}

Bappeda Kabupaten Magelang. (2011). Rencana Tata Ruang Wilayah Kabupaten Magelang 2011-2031. Magelang: Badan Perencanaan Pembangunan Daerah Kabupaten Magelang.

Chuanglin, F., Jitao, S., \& Dunjiang, S. (2007). Stability of spatial structure of urban agglomeration in China based on central place theory. Chinese Geographical Science, 173), 193-202. doi:10.1007/s11769-0070193-8.

Cruz Villamil, J. (2010). How do agglomeration economies affect the development of cities? Revista de Economía del Caribe, 6, 95-112.

Faizah, A. N., \& Hendarto, M. (2013). Analisis difusi keruangan di sekitar kawasan perkotaan Yogyakarta. Diponegoro Journal of Economics, 2(3), 1-9.

Gan, Q., Ping-yu, Z., \& Bin, J. (2006). Formation mechanism and spatial pattern of urban agglomeration in Central Jilin of China. Chinese Geographical Science, 16(2), 154-159.

Kuncoro, M. (2002). Analisis spasial dan regional: Studi aglomerasi dan kluster industri Indonesia. Yogyakarta: UPP AMP YKPN.

McDonald, J. F. (1997). Fundamentals of urban economics. Upper Saddle River, NJ: Prentice Hall.

Poyil, R. P., \& Misra, A. K. (2015). Urban agglomeration impact analysis using remote sensing and GIS techniques in Malegaon city, India. International Journal of Sustainable Built Environment,4(1), 136-144. doi:10.1016/j.jijsbe.2015.02.006.

Rongchao, G., Changhong, M., Xuexin, L., \& Deguang, C. (2007). Eco-spatial structure of urban agglomeration. Chinese Geographical Science, 171), 28-33. doi:10.1007/s11769-007-0028-7.

Soekanto, S. (2006). Sosiologi suatu pengantar. Jakarta: Raja Grafindo Persada.

Weifeng, Q., Chuanglin, F., \& Jitao, S. (2008). Measurement and spatial distribution of urban agglomeration industrial compactness in China. Chinese Geographical Science, 18(4), 291-299. doi:10.1007/s11769008-0291-2. 